\title{
OBSERVACIONES SOBRE LA FIGURA DE CUNIRAYA HUIRACOCHA EN EL MANUSCRITO Ritos y tradiciones de Huarochirí
}

\section{Introducción}

I 1 relato mítico de Cuniraya Huiracocha es, sin duda, uno de los más
conocidos del «pasado prehispánicon ${ }^{2}$ peruano gracias a las muchas ediciones del manuscrito, ${ }^{3}$ conservado en Madrid, ${ }^{4}$ a los temas interesantes y a la fusión con el personaje de Wiracocha, que lo relaciona profundamente con la tradición mitológica del sur andino.

En este pequeño ensayo, trataré de resaltar el ingreso de elementos cristianos en una tradición prehispánica, elementos que cambian un huaca, que actúa como trickester, en un dios creador, universal, según una labor empezada ya desde hacía setenta años por los misioneros y que aquí ya se reconoce como algo asumido también por la mentalidad de los indígenas.

El manuscrito quechoa Ritos y tradiciones de Huarochirí se sitúa al comienzo del siglo XVII, en el ámbito del trabajo de extirpación de las idolatrias de Francisco de Ávila. Los estudios sobre este personaje, sobre su Tratado y relación de los errores, falsos Dioses... y su obra de juez extirpador son numerosos. Según lo que afirma Taylor, parece acertado que los 
compiladores de nuestro manuscrito tenían que ser personas de su entortio, locales y comprometidas con él en la extirpación. Con respecto a otros textos, como las crónicas de muchos frailes y misioneros, la especificidad de ese manuscrito vendría a ser su mayor arraigo en la mentalidad comin de la sociedad de San Damián y de la región de Huarochití.

Analizaremos brevemente los dos momentos en que el texto se refiere a Cuniraya Huiracocha, en las primeras páginas (capítulos 1 y 2) y en el capítulo15, que explícitamente retoma el tema, pero con un cambio extraordinario de visión. Añadiremos algunas observaciones para fundamentar la tesis de la "cristianización».

Todavía como premisa, pero ya entrando en el corazón del tema, quisiera señalar cómo se inicia el manuscrito; «Si en los tiempos antiguos los antepasados de los hombres llamados indios hubieran conocido la escritura, no se habrían ido perdiendo todas sus tradiciones como ha ocurrido hasta ahora, más bien se habrian conservado, como se conservan las tradiciones y (el recuerdo de) la antigua valentía de los huiracochas que aún hoy son visiblesw.

Estamos al comienzo del siglo XVII: ya han pasado setenta años desde la llegada de los españoles y de la fe cristiana; ya los indigenas viven en reducciones, han recibido la primera evangelización; ya, con sus luces y sombras, ha empezado una sociedad diferente. El redactor del texto siente la necesidad de remarcar que ya no se puede alcanzar la tradición antigua "pura", que va perdiéndose. Él sabe que lo que escribe ya pertenece a una historia nueva. Un ejemplo interesante me parece el detalle de la expresión «los huiracochas». En el texto citado, significa «los españoles», como era uso común, visto que el redactor no siente la necesidad de explicar el porqué. La explicación de este apodo la podemos hallar en un pasaje borrado del número 47 del capitulo 2 de nuestro mismo texto, que recita: «AI llegar al 
mar [Cuniraya Huiracocha] entró y siguió su camino. Refiriéndose a este hecho, la gente de hoy dice que se dirigió hacia Castilla. En los tiempos antiguos, se decía que se fue a otro mundom.' En su nota a estas líneas, Taylor explica:

Se podria interpretar la glosa "mundo" de varias maneras: "otro tiempo-espacio", "otro país", "otra época" se trata de un pasaje sumamente interesante, ya que nos permite entrever una doble aculturación. Primero, la asociación del héroe cultural Cuniraya con su equivalente sureño Huiracocha (sintesis ya realizada probablemente en época incaica) crea una confusión en lo tocante a su destino mitológico. Como sabemos por los escritos de diversos cronistas, el Huiracocha del sur se fue hacia el mar, caminando sobre las aguas sin hundirse y, según Pachacuti Yamqui Salcamaygua, "pasó por el estrecho hacia la otra mar". Sin embargo, como se ve en la versión corregida aquí, la tradición local sobre Cuniraya difiere del otro mito. La evagelización, la asimilación entre Huiracocha y uno de los apóstoles y la consiguiente "sacralización" de los españoles llamados huiracochas, explican el hecho de que, para los indios de esa época, Cuniraya Huiracocha, entrando en el mar, se dirija hacia Castilla.'

Ya están puestos los términos de la cuestión. ¿Ein este caso específico de Huatochiri, como para los demás testimonios de la mentalidad religiosa del hombre andino (crónicas, relatos, etc.), podemos remontarnos hasta la concepción de la vida y del mundo prehispánico?

En los últimos decenios se reconstruyeton y enseñaton cosmogonias y teologías andinas basadas todas, en última instancia, en estos documentos, fruto en su totalidad de una lectura cristiana de los mitos y creencias pretéritas. Lo que el redactor de nuestro manuscrito nota al empezar su trabajo parece, para muchos de nuestros contemporáneos, pasar desapercibido.' 


\section{2. ¿Qué «personaje» es Cunitaya Huiracocha?}

Vamos a entrar ahora en el análisis sumario de los textos. En el primer capítulo se encuentra un relato bien estructurado sobre udos tiempos muy antiguos), "tiempos que correspondian a una naturaleza tropical y a un enorme crecimiento demográfico, "cuando animaba a los hombres»" un poderoso huaca ullamado Huallallo Carhuinchon, ${ }^{12}$ que después de haber desbaratado a Yanañamca y 'Tutañamca (posiblemente representaciones de un tiempo de caos y oscuridad), ${ }^{13}$ domina hasta que será vencido por otro shuaca llamado Pariacacas." Aqui, a su vez, aparece fuera del contexto, como huaca, Cuniraya, del cual se dice que no se sabe si vivió antes o después de Huallalloy Pariacaca. El texto dice:

Sin embargo sabemos que su culto está estrictamente asociado al de Huiracocha ya que los hombres cuando adomban (a Cuniraya) le dirigian (el rezo siguiente): "Cuniraya Huiracocha, animador de la tierra y del hombre, a ti no re falta nada; tú posees chacras, tú posees hombres".

En tiempos muy antiguos, antes de empezar cualquier tarea dificil, los hombres de antaño arrojaban su coca al suelo, y sin vera Huiracocha, rezaban asi: "¿ $\mathrm{Haz}$ que me acuerde de (como realizar) esta tarea y que sea hábil en su ejecución, joh Cuniraya Huiracocha!".

Se asocia, entonces, desde el primer momento Cuniraya con Huiracocha, pero se puede entrever una perplejidad, como rescata Taylot," en el redactor del manuscrito a la hora de identificar totalmente a Cuniraya con Huiracocha: el culta al primero está uestrictamente asociadon con el del segundo; se reza usin ver a Huiracochas, ${ }^{16}$ Todo hace pensar en dos 
tradiciones distintas que se han unido, pero todavía no identificado en totalidad.

En el segundo capitulo se relata «una tradición sobre Cuniraya Huiracochas: en tiempos antiguos se había disfrazado de hombre muy pobre y paseaba en medio de la gente. A él, «que animaba a todas las comunidades» le trataban como un mendigo piojoso, pero en el mismo tiempo con sus hazañas ( «con una sola palabra preparaba el terreno para las chacras y consolidaba los andenes») y «andaba humillando a los demás huacas locales".

Una doncella" (huaca, ella también) llamada Cahuillaca, muy hermosa, era el deseo de todos los huacas y huillcas, pero ella siempre los rechazaba, Cuniraya «amauta» subió como pájaro a un árbol, puso su semen en una lúcuma y la hizo caer cerca de la doncella. Ella, al comer la lúcuma, «quedó preñada sin que ningún hombre se hubiese acercado a ellas, y nueve meses más tarde dio a luz, pese a ser todavía doncella. Después de un año, quiso saber quién era el padre y convocó a todos los huacas y huillcas. También Cuniraya estaba presente; cuando Cahuillaca le dijo al niño que fuera él a reconocer a su padre, este se acercó a Cuniraya y trepó por sus piernas.

La madre no quiso aceptar que el padre fuese Cuniraya, que veía como mendigo, y se fue hacia el mar. Cuniraya la seguía ya desvelado en su esplendor, pero ella nunca se volvió: se echó al mar con su hijo y se transformó en piedra, en Pachacámac.

El camino de Cuniraya se anima de encuentros: con el cóndor, la zorrina, el puma, el zorro, el halcón, los loros; a cada uno, según sus respuestas, bendecía (si daban noticias de Cahuillaca) o maldecía, dándoles sus roles en el mundo. En este punto, al llegar a Pachacámac se une otro relato en que Cuniraya víola a una hija de Pachacámac, libera de una pileta 
los primeros peces que van a poblar el mar y logra con su astucia huir de la cólera de la madre de su víctima. Al finalizar el capítulo 2 se deja a Cuniraya «engañando a muchísimos hombres y huacas locales».

El tema de Cuniraya se retoma en el capitulo 15, que trascribo por entero:

Aquí vamos a escribir sobre lo que hemos mencionado en el segundo capítulo, es decir si Cuniraya existía antes o después de Carhuinco. Dicen que Cuniraya Huiracocha existía desde tiempos muy antiguos. Antes que el existiera, no había nada en este mundo. Fue él quien primero creólos cerros, los árboles, los rios y todas las clases de animales y las chactas para que el hombre pudiese vivir, Por ese motivo dicen que, según la tradición, Cuniraya era el padre de Pariacaca; fue él quien creó a Pariacaca. Y toda la gente afirma que de no haber sido (Pariacaca) su hijo, es probable que (Cuniraya) lo hubiera humillado. Se cuenta que con su astucia, (Cuniraya) humillaba mucho a los demás huacas locales realizando toda clase de cosas. ${ }^{19}$

\section{Algunas observaciones}

Parece innegable que asistimos a la unión de tradiciones distintas: Huiracocha se añade a Cuniraya, da fe de esto el hecho de que el nombre Cuniraya se encuentra, en los capítulos analizados, catorce veces, siete de ellas junto con Huiracocha, que, a diferencia de aquel, nunca se encuentra solo. Según la tradición local, Cuniraya viene antes de Huiracocha, como lo demuestra también la perplejidad resaltada en el mismo redactor por la identificación que él teconoce en la forma del culto, sin embargo, no lo hace como huaca. Queda como objeto de discusión si esta identificación, como propone Taylor, 
es de época incaica, fruto de la extensión de las tradiciones sur andinas, o fruto de la primera evangelización, donde la identificación de todos los héroes con Huiracocha, cada vez más asimilado con el creador, iba a constituir una base para el anuncio de la fe cristiana.

$\mathrm{Al}$ aceptar que se trata de una fusión se puede buscar el rostro original de Cuniraya. No parece, porlo menos en el capítulo 2, pero tampoco en las últimas palabras del capítulo 15, un dios creador, sino un héroe poderoso, que actùa a veces para el bien de la gente, pues animaba a las comunidades y con una sola palabra upreparaba el terreno" para las chacras y consolidaba los andenes. Y muchas veces por sus antojos, está engariando y humillanda a los demás huacas. También posee una función etiológica de explicación del origen de piedras, de animales, de huacas. Se puede reconocer uno de los artepasados míticos que todo ayllu tenía, hecho que la fenomenología religiosa reconoce típico de las civilizaciones agricolas. En la segunda parte de esta tradición, en la violación de la hija de Pachacámac y el enfrentamiento con la madre, se asemeja mucho a uno de los llamados trickesters, héroes burlones y atrevidos, díscolos, perturbadores del orden establecido, buenos y malos al mismo tiempo. El texto utiliza varias veces la palabra uamautan (vivo, astuto) ${ }^{2}$ para definir a Cuniraya. Es significativo también que en el capírulo 15 , después de hablar de Cuniraya Huiracocha como creador, salga a flote algo de su antigua naturaleza: «Se cuenta que con su astucia (amauta) humillaba mucho a los demás huacas locales realizando toda clase de cosasm."

Sin embargo, no se pueden leer estas tradiciones sin el aporte de la mentalidad cristiana. No se podría entender la profundización de tono, de espesor, del personaje Cuniraya Huiracocha del capítulo 15 sin la obra de los evangelizadores. Los términos son bíblicos, hasta en los detalles de la atmósfera de la creación que se describe «Antes que el existiera, no había 
nada en este mundo. Fue él quien primero creó los cerros, los árboles, los ríos y todas las clases de animales y las chacras para que el hombre pudiese vivin, este texto puede compararse casi literalmente con el comienzo del capítulo 2 del libro del Génesis: «El día en que Yahvé Dios hizo la tierra y los cielos, no había sobre la tierra arbusto, ni ninguna planta silvestre había brotado, pues Yahvé Dios no había hecho llover todavia sobre ella, ni habia hombre que cultuvara el suelo [...]. Yahvé hizo brotar del suelo toda clase de árboles agradables a la vista y buenos para comer...salió un río que regaba Eden [...] n." $^{21}$

Es el creador, el hacedor en el sentido cristiano: hasta el padre reconocido de las comunidades de Huarochiri, Pariacaca, que en el segundo capitulo no se sabe si vivía antes o después de Cuniraya Huiracocha, ahora es su hijo, o mejor: «[...] fue él [Cuniraya] quien creó a Pariacaca».

Otra señal de reinterpretación: cuando se describe la mujer buaca, Cahuillaca, se emplea por tres veces la palabra «doncella» (en castellano en el texto original). Se trata de un concepto que parece de alguna forma ajeno a la mentalidad andina, que no tenía palabra para comunicarlo. Esto y el cuidado en el repetir que concibió y dio a luz permaneciendo virgen hacen vislumbrar una analogía demasiado estrecha con la Virgen María como para ser casual. Obviamente, no se quiere afirmar que el redactor tenga la intención de identificar las dos vírgenes, sino que el relato revela que un lenguaje religioso católico ya se ha vuelto mentalidad en el mundo indigena, asimilando paulatinamente las antiguas historias.

\section{Conclusión}

Volviendo a la introducción del redactor del manuscrito, a su dificultad para identificarse con los indios y con los huiracochas, y viendo ese mundo 
en pleno cambio entre una historia milenaria y los tiempos de su actualidad, nos percatamos que en esos años de inicio del siglo XVII ya ha nacido un mundo distinto, una sociedad con nuevas categorías y con otras antiguas que asumen nuevos significados. Resalta la obra de la evangelización inicial (y llama la atención que se vea hasta en un texto que supuestamente busca los brotes de paganismo para extirparlos), que paulatinamente ha ido escogiendo en la tradición andina aquellos aspectos, personajes y mitos que puedan favorecer la comunicación de la fe católica por ser leídas como profecías o analogias. Esta obra, después de setenta años, da sus frutos; tradiciones de héroes se unifican y asumen características universales que los asemejan al Dios del que hablan los misioneros. Palabras y conceptos de la catequesis y de la liturgia dan un sentido nuevo al espacio-tiempo en que se vive, y proyectan también un sentido distinto sobre los ritos y las tradiciones del pasado. Puede decirse que ha surgido este fenómeno tan extraordinatio por su riqueza de expresiones y de caminos que es el «crístianismo de los Andes\%. 


\section{Notas}

'El texto utilizado, en traducción al castellano, se encuentra en' Tayjor, Gerald. Ritas y tradiaiones de Huarochiri. 2." ed. Lima: Instituto Francés de Estudios $\Lambda$ ndinos, 1999.

'Es objeto de discusión en qué medida es correcto definir así estos textos.

'Sabre todo la de José María Arguedas en Dioses y bombres de Huarochiri. Lima: Instituto de Estudios Peruanos, 1966.

'Ms 3169, «Fabulas y Ritos de los Ingan, Biblioteca Nacional de Madrid.

'Un héroe como 'Tunupa, Taparaco, Equeco, smañoso, embustero, revoltosom. Utbano, Enrique. "Tunupa, Taguapaca, Cachi. Introducción a un espacio simbólico andinom. Revisłu Andina, n. 11,1988 .

'Taylor, G., op, ait, p. 3. Es interesante notar que quien escribe toma distancia, sea de los indioso de los huiracochas: podría tratarse de un indio que ha asumido la cultura de los esparioles y que no se reconoce totalmente ni en el mundo de los antepasados ni en el mundo de los peninsulares. En otra parte del texto hay ottos puntos de critica a unas actitudes de los curas, de los encomenderos, que acteditan esta posibilidad.

'Ibidem, p. 27, nota 47.

"Tbiden.

'Ejemplo de esta equivocación: Soustelle, jacques. "Viracochas. En Poupard, Paul Dicrionuria de las Religiones. Barcelona: Herder, 1997. Un texto que no tiene umalas intenciones\%, pero que propone como cierta la interpretación de Viracocha como Dios supremo, creador, y que cita las oraciones del padre Cristóbal de Molina como textos prehispánicos originales.

"Taylor, G., op, cit, p. 5.

"Ibidem.

${ }^{12}$ Ibictem.

"Ibidem, nota L.

"Taylor, G., opt, cit, p. 9.

"Ibidem, p. 11.

${ }^{16}$ Ibidens. «Cuniraya era un Dios regional y se encontraba petrificado en la acequia de Huincopampa. Huiracocha, cuyo culto había sido propagado en todo el imperio pot los 
Incas, no tenia un adoratorio local y la gente al invocar a Cuniraya, no veya efectivamente a Huiracocha, cuyo nombre se agtegoal de Cunirayan,

"Título del capítulo; ibidem, p. 13.

"Ibidem, p. 15 ,

"Ibidem, p. 207.

${ }^{20} \mathrm{C} f$. Armas Asín, Fernanda uWiracocha, pastoral cutólica y mitología del'Titicaca. Consideraciones desde la mitografia y la andinísticsus. Anuario de Historia de la Iglesia XI. Navarra: Universidad de Navarra, 2002.

${ }^{71}$ Taylor reenvia a la definición de eastuton de la Real Academia Española: «Agudo, hábil para engañar a evitar el engan̄o o para lograr artificiosamente cualquier fins. Taylor, G., op. cit.,p. 21.

${ }^{22}$ Ibidem, p. 207.

${ }^{23}$ Gén 2, 4 . 